\title{
Patently naive
}

\author{
Intellectual-property protection is a key driver of innovation, and researchers are always keen to file patents to shield \\ their discoveries. Yet scientists often have an uninformed view of the value of their intellectual property. This naiveté \\ slows down translational research.
}

$P$

atent protection is a cornerstone of innovation, and biomedicine is no exception to this rule; securing intellectual property is a sine qua non for the development of new drugs and medical devices. It is therefore paradoxical that, even though most biomedical scientists would love to patent their work, they know very little about the rights they have over their research, how to protect their intellectual property or the value of this property in the marketplace.

An informal poll we conducted while preparing the focus on patents appearing in this issue (pp 1239-1243) disclosed that about twothirds of scientists, particularly in Europe, don't know who owns the intellectual rights to the discoveries made in their labs. A similarly high proportion don't know if there are any provisions in their job contracts assigning them any rights over their discovery. And roughly half don't even know whether they are legally entitled to open a company based on their research.

Ironically, these are the same scientists who are very keen on the idea of patenting their work, dreaming of investors approaching them to set up start-up companies of which they will become Chief Scientific Officers (CSOs) or of pharmaceutical companies willing to pay millions of dollars to license the patent. After all, if they just published in Nature or Nature Medicine, what else do investors need to see before signing the check?

Alas, things are not as simple as in this caricature because, in most cases, one's home institution is the owner of all the intellectual property that comes out of the lab. (Go ahead, check your contract.) In fact, if you want to set up a company, it is you who need to license the patent from your institution. And if you want to become the CSO, you'll be kindly asked to quit your current position before you're allowed to do so.

But let's not get ahead of ourselves. Before we even think about licenses, it's important to realize that the decision to file a patent seldom rests with the scientists, but rather with the technology transfer office (TTO) of their institution. Strangely enough, although most of the scientists we surveyed were interested in patenting their work and knew about the importance of the TTO to this end, over $60 \%$ admitted to never having interacted with that office. Worryingly, many of these researchers didn't have a particular reason to avoid the TTO beyond, "Why bother? They never listen to what we say, anyway."

TTOs have a reputation for being too conservative and disinclined to take risks. They are sometimes perceived as parochial and only willing to push technologies they have direct experience with, acting almost as roadblocks to, instead of facilitators of, translational research. Although there may be something to these accusations, scientists for their part aren't always sensitive to all the ramifications that an institution must ponder before gambling on a patent. There's the issue of monetary cost, of course. But this is only a minor factor if we consider how difficult it will be to do anything with the patent once it's granted.

For example, investors are increasingly cautious about spending any money on an idea; they often want to see preclinical and early clinical data before expressing any interest in a business plan. Companies, in turn, see your publication in a high-impact journal as little more than a good start, a start that needs to be thoroughly validated before they will commit any significant resources to it. If the target that you claim to have identified is appropriately validated, then it may indeed be worth millions. Sadly, a fact rarely mentioned in academic circles is that virtually none of what appears in the literature has been sufficiently validated to fulfill the investment standards of most companies. And when these companies take it upon themselves to do the validation, most findings don't make it through their filters.

An uncomfortable corollary of these observations is that scientists often have unrealistic expectations about the value of the intellectual property they generate in the lab. True, their research may be of the highest quality-your high-profile papers will attest to this fact—but the rules are different in the translational game and are often dictated by those who have the resources to transform an idea into a product.

Translational researchers never shy away from the chance to present their science to anyone who might want to invest in it. But they would be well advised to start listening to companies, investors and their own TTOs to develop a better understanding of what they must bring to the table in order to attract financial support. Admittedly, there are very few places where scientists can learn how to engage in this dialogue, but the excuse that provides should be cold comfort given how important this is to the progress of translational research. The creation of forums of this sort should therefore become a priority for universities and research centers alike. A high-profile paper may allow you to get your foot in the door, but it won't be enough to open it. 